This is a post-peer-review, pre-copyedit version of an article published in 'Current Psychology'. The final authenticated version is available online at: https://doi.org/10.1007/s12144-020-01056-w. The following terms of use apply: https://www.springer.com

\title{
Naturally mindful? The role of mindfulness facets in the relationship between nature relatedness and subjective well-being
}

\begin{abstract}
Nature relatedness refers to the cognitive-affective relationship with natural environments. Mindfulness is described as non-judgmental attention to the present moment and is a multi-dimensional construct consisting of interacting facets. This study aimed to clarify the mechanisms through which nature relatedness and mindfulness contribute to subjective wellbeing. Participants were 250 university students $\left(M_{\text {age }}=20.67, S D=1.99,82.4 \%\right.$ female $)$ who completed measures of nature relatedness, the five facets of mindfulness, positive and negative affect and life satisfaction. Mediation analyses revealed that of the five facets of mindfulness, only Non-Reactivity and Observing partially mediated the positive relationship between nature relatedness and positive affect, and fully mediated the positive relationship between nature relatedness and life satisfaction. Only Non-Reactivity was found to fully mediate the negative relationship between nature relatedness and negative affect. Findings suggest that when creating nature-based mindfulness interventions, it may be clinically useful develop skills that target mindfulness through Non-Reactivity and Observing.
\end{abstract}

\section{Introduction}

Emerging adults in university settings are reporting high levels of anxiety and depression symptoms (Ibrahim et al. 2013). Thus, there is a need to improve understanding of the psychological factors that contribute to mental health and well-being in university students during this developmental period. Nature relatedness, described as the affective, cognitive, and experiential connection people have with the natural environment (Nisbet et al. 2009), may have 
This is a post-peer-review, pre-copyedit version of an article published in 'Current Psychology'. The final authenticated version is available online at: https://doi.org/10.1007/s12144-020-01056-w. The following terms of use apply: https://www.springer.com

the potential to improve well-being in this population (e.g., Capaldi et al. 2014). Mindfulness is another psychological factor consistently linked with well-being, across the life span (e.g., Brown and Ryan 2003; Hanley et al. 2015; Keng et al. 2011). Mounting evidence suggests that mindfulness may meaningfully strengthen the relationship between nature relatedness and wellbeing (Howell et al. 2011; Unsworth et al. 2016). Given the need to further understand which psychological factors play protective roles in university students at risk for experiencing mental health challenges, the present study investigated the associations between nature relatedness, elements of subjective well-being, and the five facets of mindfulness in emerging adult university students. In particular, the potential explanatory roles of mindfulness facets on the relationship between nature relatedness and subjective well-being were explored.

The term "emerging adulthood" is used to describe the developmental period between ages 18-29, according to Arnett's model of emerging adulthood (Arnett 2000; Arnett et al. 2014). Emerging adulthood is often conceptualized as the transitional life stage between adolescence and adulthood, a recent phenomenon that is particularly pronounced in high-income countries (Arnett 2011). Young people in industrialized societies are pursuing post-secondary education more frequently and for longer periods of time, as well as marrying and becoming parents at older ages (e.g., Arnett 2007; Lanz and Tagliabue 2007; Macek et al. 2007; Mayseless and Scharf 2003). Linked to these societal changes, the period of emerging adulthood is marked by the sense that many individuals in their late teens and early 20 s have that they are no longer teenagers, but at the same time, are only partly adults (Arnett 2007).

Notably, there is a pattern of increase in mental health disorders during the emerging adulthood period. In Canada, emerging adults, especially those 25 years old and younger, are more likely than any other age group to experience mental illness and/or substance use disorders 
This is a post-peer-review, pre-copyedit version of an article published in 'Current Psychology'. The final authenticated version is available online at: https://doi.org/10.1007/s12144-020-01056-w. The following terms of use apply: https://www.springer.com

(Statistics Canada 2015; Center for Behavioral Health Statistics and Quality 2016; Pearson and Ali 2013). These findings transfer to emerging adults in university settings, where approximately $30 \%$ of students experience clinical levels of depression, and about $50 \%$ report feeling so depressed that they have difficulty functioning (Ibrahim et al. 2013). Additionally, a survey across 41 Canadian university campuses found that around $90 \%$ of students reported feeling overwhelmed within the last year, $65 \%$ reported feelings of intense anxiety, and $44 \%$ reported feeling depressed (Canadian Association of College and University Student Services and Canadian Mental Health Association 2013). With record levels of mental health challenges being disclosed by emerging adult university students, campus mental health services have been struggling to keep up with student demands. Therefore, there is a clear need for preventative programs aimed at cultivating mental health resilience through improved coping skills (Auerbach et al. 2018). However, it is first necessary to improve understanding of the mechanisms that contribute to mental health and well-being in emerging adult university students in order for these programs to operate successfully.

Given the increased risk for mental health challenges during the emerging adulthood period, it is important to consider how positive psychological outcomes, such as well-being, are influenced in this population. As a construct, well-being is widely defined and interpreted. However, it has also been evaluated through precise theoretical models, such as subjective wellbeing. Subjective well-being, defined as individuals' subjective appraisal of their quality of life and happiness, is often described as frequent positive affect, infrequent negative affect, and high levels of satisfaction with life (Diener 2000). Individuals' reports of subjective well-being usually oscillate around a set point; in turn, this set-point can be influenced by adaption to life circumstances (Diener 2000). 
This is a post-peer-review, pre-copyedit version of an article published in 'Current Psychology'. The final authenticated version is available online at: https://doi.org/10.1007/s12144-020-01056-w. The following terms of use apply: https://www.springer.com

One factor that has been proposed to be meaningfully linked to well-being is connection with nature. The Biophilia Hypothesis (Wilson 1984), a seminal work in the field of environmental psychology, posited that human psychological health and happiness is related to connection to the natural environment. Aligned with the notion that natural settings are necessary for human thriving (Orians 1980), nature has been found to elicit strong positive responses in individuals across the globe in both rural and urban settings (see Kaplan and Kaplan 1989; McMahan and Estes 2015 for review). This hypothesis has been corroborated by a variety of studies investigating the relationship between connection with nature and human psychological health (e.g., Mayer et al. 2009; Nisbet et al. 2011; Zelenski and Nisbet 2014).

Nature relatedness (also referred to as nature connectedness, nature connection) is defined as the trait-like cognitive, affective, and experiential relationship individuals have with their natural environment, including the appreciation and understanding of humans' interconnectedness with all other living things (Nisbet et al. 2009). As a construct, nature relatedness goes beyond mere exposure to nature by taking into account the individual's perception of their interconnectedness with nature (Frumkin 2013). There is a growing body of evidence linking nature relatedness with overall subjective well-being (Mayer et al. 2009; Nisbet et al. 2011). Additionally, a recent meta-analysis found that higher levels of nature relatedness were connected to positive relationships with vitality, life satisfaction, and positive affect (Capaldi et al. 2014). As such, nature relatedness shows significant promise as a factor to target in the improvement of university student well-being.

To date, research tends to focus on understanding exposure to nature, with considerable work conducted to determine mediators and moderators that affect the relationship between nature exposure and well-being outcomes (De Vries et al. 2003; Shanahan et al. 2015); however, 
This is a post-peer-review, pre-copyedit version of an article published in 'Current Psychology'. The final authenticated version is available online at: https://doi.org/10.1007/s12144-020-01056-w. The following terms of use apply: https://www.springer.com

this work may neglect the differing ways in which people value and connect with the natural environment. To better understand how nature relatedness contributes to well-being and healthy coping in emerging adult university students, it is necessary to elucidate the mental state of the individual when relating to nature. Relating to nature with a contemplative and body-anchored mind state, as in meditative mindfulness, may explain the effects of nature relatedness on wellness through complete presence in the moment.

Mindfulness, as a construct, has been defined in a variety of ways (for in-depth reviews of prevailing conceptualizations, see: Bodhi 2011; Dunne 2015; Gethin 2011; Hart et al. 2013; Khoury et al. 2017). From the lens of western mindfulness-meditation, mindfulness is commonly described as the process of purposefully, and with acceptance, paying attention nonjudgementally to the present moment (Kabat-Zinn 2003). It can be described as both a state, reflecting moment-to-moment experiences of mindfulness, or a disposition (i.e., a general tendency to be mindful; Brown and Ryan 2003). Additionally, mindfulness can be thought of as a multi-dimensional construct consisting of numerous interacting facets (e.g., Baer et al. 2006). Investigation employing a multi-dimensional model of mindfulness is important in order to obtain detailed information about the complex relationships between nature relatedness, mindfulness, and well-being. Despite the plenitude of research demonstrating the benefits of mindfulness, the precise mechanisms behind these benefits remain unclear. Baer et al. 2006) posited that mindfulness is composed of five interacting facets: non-reactivity to inner experience, non-judgment of inner thoughts and feelings, acting with awareness, describing experiences, and observing. Although preliminary evidence suggests that these facets differentially predict adaptive and maladaptive psychological outcomes (e.g., self-compassion, emotional intelligence, dissociation) in general population adults and university students (e.g., 
This is a post-peer-review, pre-copyedit version of an article published in 'Current Psychology'. The final authenticated version is available online at: https://doi.org/10.1007/s12144-020-01056-w. The following terms of use apply: https://www.springer.com

Baer et al. 2006; Brown et al. 2015a), it is still uncertain which aspects of dispositional mindfulness are associated with greater positive outcomes over time.

Research has demonstrated a relationship between indices of well-being and mindfulness. In both undergraduate students and the general population, extensive literature has linked both dispositional and state mindfulness with improved mental health outcomes (e.g., see Creswell 2017 for review; see Khoury et al. 2013, and Regehr et al. 2013 for meta-analysis). Furthermore, greater levels of dispositional mindfulness have been associated with increased positive affect, life satisfaction, empathy, and decreased negative affect up to one year after mindfulness-based interventions (Shapiro et al. 2011). Importantly, higher levels of dispositional mindfulness have been linked to increased subjective well-being, decreased symptoms of anxiety and depression, and improved capability to adaptively and flexibly regulate behavioural, emotional, and physiological responses to stressful situations (Brown et al. 2007; Cash and Whittingham 2010; Kadziolka et al. 2016; Keng et al. 2011; Schutte and Malouff 2011; Soysa and Wilcomb 2015).

In addition to its relationship with well-being, mindfulness has been cited as a prerequisite for the cultivation of nature relatedness, with a recent meta-analysis across 12 samples indicating a consistent, positive association between connection with nature and mindfulness (Schutte and Malouff 2018). Preliminary studies examining nature connectedness show higher levels of mindfulness to be positively related with improved psychological outcomes (Howell et al. 2011; Lin et al. 2014; Richardson and Hallam 2013). Furthermore, evidence indicates that nature exposure may not increase well-being through nature relatedness without mindful awareness (Mantler and Logan 2015). Unsworth and colleagues investigated the relative influence of mindfulness meditation (described as meditation involving focused attention on thoughts, perceptions and sensory experiences of the current moment), and nature exposure, on 
This is a post-peer-review, pre-copyedit version of an article published in 'Current Psychology'. The final authenticated version is available online at: https://doi.org/10.1007/s12144-020-01056-w. The following terms of use apply: https://www.springer.com

self-nature interconnectedness; they found that mindful meditation in nature strengthened nature relatedness (Unsworth et al. 2016). Therefore, it is possible that the association between nature relatedness and elements of subjective well-being is at least partially explained or mediated by individuals' reports of dispositional mindfulness facets. Given the strong links between nature relatedness, mindfulness, and well-being in emerging adult university students, there is a need to clarify understanding of the relationships between these psychological factors. Research investigating the associations between connection with nature and dimensions of mindfulness points to stronger relationships between observing and non-reactivity and nature connection (e.g., Barbaro and Pickett 2016; Hanley et al. 2017). As such, it is likely that these two mindfulness facets will play larger explanatory roles in the relationship between nature relatedness and subjective well-being. In sum, it is necessary to investigate the specific effects of the different facets of mindfulness on the relationship between nature relatedness and subjective well-being in order to further clarify the quality of their associations in emerging adult university students.

\section{Overview of the Present Study}

Given the elevated risk for mental health disorders in the emerging adulthood period and the potential for positive psychological factors, such as nature relatedness and mindfulness, to improve mental health outcomes (e.g., subjective well-being), this research focuses on clarifying the potentially mediating relationship of the five facets of mindfulness on the association between nature relatedness and subjective well-being.

As a preliminary step in assessing the potential influence of specific dispositional mindfulness facets on the relationship between nature relatedness and subjective well-being in 
This is a post-peer-review, pre-copyedit version of an article published in 'Current Psychology'. The final authenticated version is available online at: https://doi.org/10.1007/s12144-020-01056-w. The following terms of use apply: https://www.springer.com

emerging adulthood, the first objective of the current study was to assess the relationships between nature relatedness, the five facets of dispositional mindfulness (non-reactivity to inner experience, non-judging of inner experience, acting with awareness, describing, and observing), and dimensions of subjective well-being (frequency of positive and negative affect, and life satisfaction). Specifically, it was hypothesized that higher reports of nature relatedness would be associated with higher levels of the five facets of dispositional mindfulness and overall subjective well-being (high life satisfaction and positive affect, low negative affect) (H1). Additionally, reports of higher levels of the five facets of dispositional mindfulness were hypothesized to be associated with better overall subjective well-being (H2).

The second objective of the present study was to evaluate the influence of the five facets of dispositional mindfulness as possible mediators between nature relatedness and the dimensions of subjective well-being (positive affect, negative affect, and life satisfaction). This objective was exploratory in nature and thus a priori hypotheses were not made; however, based on limited existing research, it was anticipated that the observing and non-reactivity facets would likely play larger roles in the relationship between nature relatedness and subjective well-being.

\section{Method}

\section{Procedure}

University student participants were recruited from the three following sources: (1) via email, using an existing database of students attending a large, research-intensive Canadian university who participated in previous studies conducted by the research team and agreed to be contacted for future studies; (2) flyers distributed throughout the buildings of each of the departments at the same research-intensive Canadian university campus, on university social 
This is a post-peer-review, pre-copyedit version of an article published in 'Current Psychology'. The final authenticated version is available online at: https://doi.org/10.1007/s12144-020-01056-w. The following terms of use apply: https://www.springer.com

media pages and through departmental listservs; and (3) through the undergraduate psychology Participant Pool at the same Canadian university. Recruitment was designed in order to reach a variety of undergraduate students from differing faculties and programs. The survey was completed online. Participants recruited via the Participant Pool were compensated via course credits. All other participants were offered entry into a raffle to receive one of 12 prizes of $\$ 25$. This study was approved by the university's Institutional Ethics Review Board.

\section{Participants}

A total of 292 participants at least partially responded to the online survey. However, following data cleaning procedures outlined below in the results section, the final sample size used for analyses consisted of 250 university students between the ages of 18 to $29\left(M_{\text {age }}=20.67\right.$ years, $S D=1.993)$. The majority of participants reported being female $(82.4 \%)$ and white $(62.4 \%)$. When asked whether they felt they had reached adulthood, most participants reported "in some ways yes, in some ways no" (71.6\%). Furthermore, most participants reported either living with their parents (40.2\%) or with roommates (37.3\%), and the majority of participants reported being unemployed (64.0\%).

\section{Measures}

\section{Dispositional Mindfulness}

The Five Facets of Mindfulness Questionnaire (FFMQ; Baer et al. 2006; Bohlmeijer et al. 2011) a 39-item self-report measure consisting of five subscales each assessing a specific facet of dispositional mindfulness: acting with awareness, describing, observing, non-reactivity, and nonjudgmental acceptance, was used to assess participants' levels of dispositional mindfulness. Items included "I'm good at finding words to describe my feelings" and "I watch my feelings 
This is a post-peer-review, pre-copyedit version of an article published in 'Current Psychology'. The final authenticated version is available online at: https://doi.org/10.1007/s12144-020-01056-w. The following terms of use apply: https://www.springer.com

without getting carried away by them.” Participants rated their responses on a 5-point scale $(1=$ never or very rarely true to $5=$ very often or always true $)$. Higher scores on the FFMQ indicate higher levels of dispositional mindfulness. The FFMQ has high internal consistency with Cronbach alphas ranging from .73 to .91 , high test-retest reliability, as well as discriminant, convergent, and criterion validity (Baer et al. 2006). The internal consistency of this 39-item scale was found to be adequate for the present study $(\alpha=0.90)$. Composite scores were calculated and acceptable for each facet - non-reactivity $(\alpha=0.81)$, non-judgment $(\alpha=0.93)$; acting $(\alpha=0.91)$, describing $(\alpha=0.91)$, and observing $(\alpha=0.81)$.

\section{Nature Relatedness}

The Nature Relatedness Scale (NRS; Nisbet et al. 2009) was used to assess levels of nature relatedness. The NRS is a 21-item measure assessing individuals' trait-like affective, cognitive, and experiential relationship with their natural environment. Items (e.g., "I take notice of wildlife wherever I am") are rated on a Likert-style scale with $1=$ disagree strongly and $5=$ agree strongly, with higher total scores indicating higher levels of nature connectedness. Higher scores on the NRS imply higher levels of nature relatedness. The questionnaire was found to demonstrate good reliability in this study (Cronbach's $\alpha=0.84$ ) which mirrors its original reliability levels $(\alpha=0.87)$.

\section{Positive and Negative Affect}

The Positive and Negative Affect Schedule (PANAS; Watson et al. 1998) was used to assess participants' general dispositional tendency to experience positive and negative affect. The PANAS is an extensively used self-report measure and is comprised of two 10-item scales assessing individuals' levels of positive affect and negative affect on a 5-point scale ranging 
This is a post-peer-review, pre-copyedit version of an article published in 'Current Psychology'. The final authenticated version is available online at: https://doi.org/10.1007/s12144-020-01056-w. The following terms of use apply: https://www.springer.com

from very slightly or not at all to extremely, according to the specific time point indicated (e.g., the past few weeks, generally, right now, etc.). Participants in the present study based their answers on the time frame of "the past few weeks". The positive affect and negative affect subscales each consist of a list of emotions (e.g., "interested", "alert", "upset”, "guilty”), whereby 10 items refer to positive affect and another 10 refer to negative affect. Elevated scores indicate higher levels of positive or negative affect. The PANAS has strong internal consistency, with coefficient alphas ranging from .86 to .90 for the positive affect scale and .84 to .87 for the negative affect scale, as well as external validity with measures of depression, anxiety, dysfunction, and general distress (Watson et al. 1998). In the present study, the PANAS had a Cronbach's alpha of .84 for negative affect and .91 for positive affect, thereby demonstrating acceptable reliability compared to that found in the original sample.

\section{Life Satisfaction}

The Satisfaction With Life Scale (SWLS; Diener et al. 1985) was used to assess individuals' general satisfaction with life. It is a self-report scale comprised of 5 items (e.g., "In most ways, my life is close to my ideal"). Items use a 7-point scale ranging from "strongly agree" to "strongly disagree" with higher scores indicating greater satisfaction with life. Higher scores on the SWLS indicate greater satisfaction with life. The SWLS has been found to have strong internal consistency (coefficient $\alpha=0.87$ ), temporal stability (coefficient $\alpha=0.82$ ) and convergent and discriminant validity (Pavot and Diener 1993). The SWLS was found to have good reliability in the present study (Cronbach's $\alpha=0.88$ ).

\section{Data Analysis}


This is a post-peer-review, pre-copyedit version of an article published in 'Current Psychology'. The final authenticated version is available online at: https://doi.org/10.1007/s12144-020-01056-w. The following terms of use apply: https://www.springer.com

All data were analyzed using SPSS 21, as well as PROCESS, a program developed for SPSS by Hayes (2014). Pearson's biserial correlations were used to examine the associations between natural relatedness, each of the five facets of dispositional mindfulness, and the three domains of subjective well-being. Subsequently, separate mediation analyses were run using the bootstrapping procedure (5000 resamples) with PROCESS for SPSS (model 4; Hayes 2017).

\section{Results}

Prior to running analyses, the data were initially screened to remove all participants who did not provide their age $(n=1)$, or were not 18 to 29 years old $(n=3)$. Upon noting similar patterns after visual inspection across demographic variables, participants who did not complete at least half of the survey were removed $(n=32)$. Results from a Missing Value Analysis revealed that all variables had less than $5 \%$ of missing values; therefore, the data could be assumed to be missing completely at random. As expected, the same pattern of results was obtained for analyses conducted using list-wise deletion compared to using the expectationmaximization method (Tabachnick et al. 2007). Therefore, missing values were imputed using the expectation-maximization method in order to preserve statistical power. Finally, five individuals were removed for being univariate outliers, and one individual was removed for being a multivariate outlier.

Results from Pearson biserial correlations examining the hypothesized positive association of nature relatedness with the five facets of dispositional mindfulness and overall subjective well-being (H1) revealed partial support for $\mathrm{H} 1$, whereby a significant positive association was found between nature relatedness and positive affect, life satisfaction, and the non-reactivity, describing, and observing facets of mindfulness. However, nature relatedness was 
This is a post-peer-review, pre-copyedit version of an article published in 'Current Psychology'. The final authenticated version is available online at: https://doi.org/10.1007/s12144-020-01056-w. The following terms of use apply: https://www.springer.com

not significantly related to negative affect, or the non-judging and acting with awareness mindfulness facets, which was contrary to expected (see Table 1 for descriptive statistics; see Table 2 for correlation matrix). Similarly, results from Pearson biserial correlations partially supported $\mathrm{H} 2$ which was to investigate whether the five facets of mindfulness were positively associated with subjective well-being. Higher levels of all five facets of dispositional mindfulness were significantly associated with higher levels of life satisfaction and positive affect. However, only higher levels of non-reactivity, non-judging, acting with awareness, and describing were significantly associated with less frequent reports of negative affect. Observing was not significantly related to negative affect (see Table 2).

To test the mediational role of the five distinct facets of mindfulness in the relationship between nature relatedness and subjective well-being, separate mediation analyses for each of the five mindfulness facets were run for each of the three aspects of subjective well-being, (i.e., positive affect, life satisfaction, and negative affect). The individual pathways for each of the models are presented with standardized coefficients in Table 3, see Figs. 1, 2, 3, 4, 5, 6, 7, 8, 9, 10, 11, 12, 13, 14, 15, 16 of Appendix 1 for model illustrations.

Results revealed that non-reactivity partially positively mediated the relationship between nature-relatedness and positive affect $(a b=.63 ; S E=.30 ; 95 \% \mathrm{CI}[.10,1.27])$, and fully positively mediated the relationship between nature relatedness and life satisfaction $(a b=.58$, $S E=.27 ; 95 \%$ CI $[.11,1.17])$. Additionally, non-reactivity fully negatively mediated the relationship between nature relatedness and negative affect $(a b=-.60 ; S E=.29 ; 95 \% \mathrm{CI}[-1.22$, $-.93]$ ). 
This is a post-peer-review, pre-copyedit version of an article published in 'Current Psychology'. The final authenticated version is available online at: https://doi.org/10.1007/s12144-020-01056-w. The following terms of use apply: https://www.springer.com

When looking at observing, a partial mediation was found for the relationship between nature relatedness and positive affect $(a b=1.41 ; S E=.45 ; 95 \% \mathrm{CI}[.62,2.40])$, and a full mediation was found for the relationship between nature relatedness and life satisfaction $(a b=.82 ; S E=.37 ; 95 \%$ CI $[.02, .24])$. However, no mediation was found for the relationship between nature relatedness and negative affect $(a b=.02 ; S E=.35 ; 95 \% \mathrm{CI}[-.64, .72])$.

No mediating effects of the non-judging, describing, and acting with awareness mindfulness facets were found for the relationship between nature relatedness and any of the three aspects of subjective well-being (i.e., positive affect, life satisfaction, and negative affect). However, a power analysis conducted on MPlus (version 8.4) revealed that, while direct effects were adequately powered (>80\%), indirect effects were underpowered (59\%); therefore, insignificant effects must be interpreted with caution due to risk of Type II error.

\section{Discussion}

\section{General Discussion}

The present study aimed to determine the associations between nature relatedness, dispositional mindfulness, and factors related to subjective well-being. Specifically, higher levels of nature relatedness were hypothesized to be associated with higher levels of the five facets of mindfulness, and overall subjective well-being in university students (H1). H1 was partially supported, with a significant positive relationship found between nature relatedness and positive affect, life satisfaction, and the non-reactivity, describing, and observing facets of mindfulness. Contrary to our prediction, nature relatedness was not significantly associated with negative affect, nor the non-judging and acting with awareness mindfulness facets. Additionally, it was hypothesized that the five facets of dispositional mindfulness would be positively associated with 
This is a post-peer-review, pre-copyedit version of an article published in 'Current Psychology'. The final authenticated version is available online at: https://doi.org/10.1007/s12144-020-01056-w. The following terms of use apply: https://www.springer.com

university student well-being (H2). Results indicated that the five facets of dispositional mindfulness were related with overall subjective well-being (i.e., higher life satisfaction, more frequent positive affect, less frequent negative affect), except for observing, which was not associated with negative affect. This is consistent with previous research indicating unclear associations between the observing facet and maladaptive characteristics (Baer et al. 2006).

Although the relationship between nature relatedness and well-being has been previously established in studies with university student samples (e.g., Capaldi et al. 2014; Mayer et al. 2009; Nisbet et al. 2011), it appears that in this sample of predominately female emerging adult university students, nature relatedness was associated with specific aspects of well-being. In particular, higher levels of nature relatedness were associated with higher levels of positive affect and life satisfaction, but were not associated with negative affect. Therefore, it appears that, in female university students, connection with nature may be more likely to be associated with increases in positive psychological outcomes as opposed to decreases in negative symptomatology. This is consistent with meta-analytic findings linking stronger connection to nature with higher levels of positive affect, vitality, and life satisfaction in university students (Capaldi et al. 2014). In line with the broaden-and-build theory (Fredrickson 1998), which posits that positive emotions distinctly hold the capacity to broaden momentary thought-action inventories and consequently set people on growth trajectories that build enduring personal resources, the more the experience of positive emotions is enhanced, the easier it becomes to expand psychological resources. Thus, in the context of university student health service provision, nature relatedness may be particularly useful to target in the development of preventative mental health programs focused on improving well-being, as opposed to reducing negative mental health outcomes. 
This is a post-peer-review, pre-copyedit version of an article published in 'Current Psychology'. The final authenticated version is available online at: https://doi.org/10.1007/s12144-020-01056-w. The following terms of use apply: https://www.springer.com

The finding that non-reactivity, observing, and describing were significantly associated with nature relatedness are consistent with a study by Barbaro and Pickett (2016) examining the effect of nature connection on the relationship between mindfulness facets and proenvironmental behaviour. Barbaro and Pickett (2016) found that connection with nature was only significantly related to observing, non-reactivity, and describing in a sample of emerging adultaged undergraduate psychology students. Interestingly, when examining these same relationships in an online sample with a wider age distribution, the only facet that was not significantly linked to nature connection was non-judging (Barbaro and Pickett 2016). Additionally, in a study by Hanley et al. (2017), observing and non-reactivity were the only facets of mindfulness found to be associated with deeper connections to nature within a sample of adults in the USA. Finally, in a recent meta-analysis, it was found that the relationship between nature connection and mindfulness was slightly weaker in younger, college samples (Schutte and Malouff 2018). This weaker relationship could be attributable to the salience of particular mindfulness facets in explaining the association between connection with nature and mindfulness in this age group. Drawing from this literature, the findings from the present study appear to suggest that nonreactivity, observing and to a lesser extent describing may be particularly relevant when examining nature connection in female university students during emerging adulthood.

Furthermore, this study explored the role of the non-reactivity, non-judging, acting with awareness, describing, and observing facets of dispositional mindfulness in the relationship between nature relatedness and subjective well-being in university students. Findings from mediation analyses revealed that non-reactivity and observing helped to explain the overall positive relationship between nature relatedness and subjective well-being. Both non-reactivity and observing were found to partially mediate the relationship between nature relatedness and 
This is a post-peer-review, pre-copyedit version of an article published in 'Current Psychology'. The final authenticated version is available online at: https://doi.org/10.1007/s12144-020-01056-w. The following terms of use apply: https://www.springer.com

positive affect, and fully mediate the relationship between nature relatedness and life satisfaction. In other words, nature relatedness contributed to increases in the frequency of experience of positive affect partially through higher levels of non-reactivity, with the same pattern found for observing. However, due to the partial nature of these mediations, even when accounting for the effect of non-reactivity or observing, nature relatedness was still positively associated with positive affect. Meanwhile, non-reactivity and observing both fully explained the positive relationship between nature relatedness and life satisfaction, indicating that once non-reactivity or observing were controlled for, nature relatedness no longer had a direct positive relationship with life satisfaction. Interestingly, non-reactivity was found to fully negatively mediate the relationship between nature relatedness and negative affect, indicating that nature relatedness has a significant effect on negative affect solely through the non-reactivity facet of mindfulness. This finding appears to suggest that the more that female university students, in particular, are connected to nature, the less they experience negative affect, but that this may only be occurring due to nature connectedness decreasing their reactivity to experience.

Of particular importance, non-reactivity and observing were found to significantly mediate the relationship between nature relatedness and subjective well-being. It seems that these mindfulness facets may be especially central in explaining the positive association between nature connection and well-being in female university students. Non-reactivity can be conceptualized as the ability to refrain from engaging in impulsive responses to experiences and has been linked to lower levels of absent-mindedness (Baer et al. 2006). This ability to slow down and appreciate what is happening in the moment might serve as an explanation for the predictive relationship between appreciating and feeling connected to the natural environment and enhanced levels of positive affect, satisfaction with life, and decreased negative affect in 
This is a post-peer-review, pre-copyedit version of an article published in 'Current Psychology'. The final authenticated version is available online at: https://doi.org/10.1007/s12144-020-01056-w. The following terms of use apply: https://www.springer.com

female emerging adult university students. Whereas the other components of mindfulness reflect attention to internal cognitions, observing is uniquely linked to attention to external stimuli (Baer et al. 2006). Thus, observing may explain the predictive relationship of nature relatedness with positive affect and life satisfaction through producing greater attention to environmental stimuli, thereby potentially strengthening the connection one feels with nature and consequently increasing levels of life satisfaction and frequency of positive affect in female emerging adult university students.

When developing nature-based mindfulness interventions for university students, the results from this study suggest that it may be important to focus on the development of skills that target teaching and learning mindfulness through the non-reactivity and observing facets. Research in both general and university populations has begun to investigate the ways in which mindfulness training could act as a protective factor against mental health problems through enhancing positive psychological functioning (Bajaj and Pande 2016; Brown et al. 2015b; Galante et al. 2018; Gallego et al. 2014; Grossman et al. 2004; Khoury et al. 2013). The present findings build on this growing body of research through clarifying which specific components of mindfulness might serve to explain the positive predictive relationship of nature connection with well-being in female emerging adult university students. Given these promising preliminary findings, future longitudinal studies examining the mediating relationship of mindfulness facets on the association between nature relatedness and well-being in varied emerging adulthood samples is warranted.

\section{Limitations and Future Directions}


This is a post-peer-review, pre-copyedit version of an article published in 'Current Psychology'. The final authenticated version is available online at: https://doi.org/10.1007/s12144-020-01056-w. The following terms of use apply: https://www.springer.com

Some limitations in the present study bear mentioning. Foremost, due to the crosssectional nature of the study, it is not possible to infer causation from the results. Longitudinal designs are necessary to elucidate the role of specific components of mindfulness in the relationship between nature relatedness and well-being. However, based on available literature, we argue for the directionality that connection to nature increases well-being through the nonreactivity and observing facets of mindfulness, due to mindfulness explaining the positive relationship between nature connection (Schutte and Malouff 2018), and well-being outcomes (e.g., Ryan et al. 2010).

Furthermore, although the measures used in this study were well-validated and widely used, the use of self-report measures is a limitation of this study's design, as self-reports can contain recall and reporting errors. Future research examining the impact of mindfulness facets on the relationship between nature connection and well-being in emerging adults using daily diary methodology is warranted. Although still self-report, this method would examine levels of nature relatedness, well-being, and mindfulness in real time, thereby reducing recall bias. This methodology could also enable examination of university students' nature-based behaviour, for example, by measuring the weekly frequency that they access natural locations. Preliminary studies in the area of nature connection and well-being show support for the efficacy of diarybased data collection (e.g., Passmore and Howell 2014). Additionally, studies examining the effect of nature-based mindfulness interventions on levels of mindfulness, nature relatedness, and well-being in emerging adults are necessary in order to clarify whether these factors can be augmented through training.

The study's sample was restricted to self-selected university students and was predominantly female. Thus, the degree to which these findings are generalizable to the wider 
This is a post-peer-review, pre-copyedit version of an article published in 'Current Psychology'. The final authenticated version is available online at: https://doi.org/10.1007/s12144-020-01056-w. The following terms of use apply: https://www.springer.com

population of emerging adults, or to males, is unknown. Future studies examining non-student community samples of emerging adults, along with gender-balanced samples, are warranted.

Finally, our study was underpowered for indirect effects. Although we cannot be sure that the insignificant indirect effects for non-judging, describing, and acting with awareness are truly non-significant due to lack of power, it is still valuable to note that the indirect effects of nonreactivity and observing on the relationship between nature relatedness and subjective well-being were demonstrating significance. Participant recruitment was undertaken over a period of three months. The project team recruited as heavily as possible at this time; however, of the initial 292 who agreed to participate in the study, 32 completed less than half of the study's measures. While this study's sample size is comparable to similar studies in the field, future studies with larger samples are warranted in order to ensure adequately powered statistical analyses.

\section{Conclusion}

Findings from this study suggest that, in a sample of emerging adult university students, the relationship between nature relatedness and elements of subjective well-being may be in part explained by the non-reactivity and observing facets of dispositional mindfulness. Specifically, higher levels of non-reactivity and observing may partially explain the positive influence of nature relatedness on experiences of positive affect, and fully explain its influence on life satisfaction. Additionally, non-reactivity may fully account for the association between nature connection and negative affect. Nature involvement has been identified as one of the few lifestyle interventions that is well-evidenced for improving well-being, yet remains potentially under-utilized by practicing psychologists (Walsh 2011). Findings from this research point to the utility of targeting mindfulness facets and connection with nature as a pathway to enhance well- 
This is a post-peer-review, pre-copyedit version of an article published in 'Current Psychology'. The final authenticated version is available online at: https://doi.org/10.1007/s12144-020-01056-w. The following terms of use apply: https://www.springer.com

being in university students, and as a relatively cost-effective and accessible treatment modality for university mental health service providers. Furthermore, given that dispositional mindfulness is a dynamic psychological factor that can be modified through practice (Khoury et al. 2013; Khoury et al. 2015), the present study helps to clarify the specific elements of mindfulness that might be important for university-based health services to target in the development of naturebased mindfulness interventions in emerging adults.

\section{References}

Arnett, J. J. (2000). Emerging adulthood: A theory of development from the late teens through the twenties. American Psychologist, 55(5), 469-480. https://doi.org/10.1037//0003066X.55.5.469.

Arnett, J. J. (2007). Emerging adulthood: What is it, and what is it good for? Child Development Perspectives, 1(2), 68-73. https://doi.org/ 10.1111/j.1750-8606.2007.00016.x.

Arnett, J. J. (2011). Emerging adulthood(s): The cultural psychology of a new life stage. In L. A. Jensen (Ed.), Bridging cultural and devel- opmental approaches to psychology: New syntheses in theory, re- search, and policy (pp. 255-275). New York: Oxford University Press.

Arnett, J. J., Žukauskienė, R., \& Sugimura, K. (2014). The new life stage of emerging adulthood at ages 18-29 years: Implications for mental health. The Lancet Psychiatry, 1(7), 569576. https://doi.org/10. 1016/s2215-0366(14)00080-7. 
This is a post-peer-review, pre-copyedit version of an article published in 'Current Psychology'. The final authenticated version is available online at: https://doi.org/10.1007/s12144-020-01056-w. The following terms of use apply: https://www.springer.com

Auerbach, R. P., Mortier, P., Bruffaerts, R., Alonso, J., Benjet, C., Cuijpers, P., et al. (2018).

WHO world mental health surveys inter- national college student project: Prevalence and distribution of mental disorders. Journal of Abnormal Psychology, 127(7), 623-638. https://doi.org/10.1037/abn0000362.

Baer, R. A., Smith, G. T., Hopkins, J., Krietemeyer, J., \& Toney, L. (2006). Using self-report assessment methods to explore facets of mindfulness. Assessment, 13(1), 27-45. https://doi.org/10.1177/1073191105283504.

Bajaj, B., \& Pande, N. (2016). Mediating role of resilience in the impact of mindfulness on life satisfaction and affect as indices of subjective well-being. Personality and Individual Differences, 93, 63-67. https://doi.org/10.1016/j.paid.2015.09.005.

Barbaro, N., \& Pickett, S. M. (2016). Mindfully green: Examining the effect of connectedness to nature on the relationship between mind- fulness and engagement in pro-environmental behavior. Personality and Individual Differences, 93, 137-142. https://doi.org/10.1016/j. paid.2015.05.026.

Bodhi, B. (2011). What does mindfulness really mean? A canonical per- spective. Contemporary Buddhism, 12(1), 19-39. https://doi.org/10. 1080/14639947.2011.564813.

Bohlmeijer, E., Ten Klooster, P. M., Fledderus, M., Veehof, M., \& Baer, R. (2011). Psychometric properties of the five facet mindfulness questionnaire in depressed adults and development of a short form. Assessment, 18 (3), 308-320. https:// doi.org/ 10.1177 / 1073191111408231. 
This is a post-peer-review, pre-copyedit version of an article published in 'Current Psychology'. The final authenticated version is available online at: https://doi.org/10.1007/s12144-020-01056-w. The following terms of use apply: https://www.springer.com

Brown, D. B., Bravo, A. J., Roos, C. R., \& Pearson, M. R. (2015a). Five facets of mindfulness and psychological health: Evaluating a psychological model of the mechanisms of mindfulness. Mindfulness, 6(5), 1021-1032. https://doi.org/10.1007/s12671- 014-03494.

Brown, K. W., Creswell, J. D., \& Ryan, R. M. (2015b). Handbook of mindfulness: Theory, research and practice. New York: The Guilford Press.

Brown, K. W., \& Ryan, R. M. (2003). The benefits of being present: Mindfulness and its role in psychological well-being. Journal of Personality and Social Psychology, 84(4), 822-848. https://doi. org/10.1037/0022-3514.84.4.822.

Brown, K. W., Ryan, R. M., \& Creswell, J. D. (2007). Mindfulness: Theoretical foundations and evidence for its salutary effects. Psychological Inquiry, 18(4), 211-237. https://doi.org/10.1080/10478400701598298.

Capaldi, C. A., Dopko, R. L., \& Zelenski, J. M. (2014). The relationship between nature connectedness and happiness: A meta-analysis. Frontiers in Psychology, 5, 976. https://doi.org/10.3389/fpsyg. 2014.00976.

Canadian Association of College \& University Student Services and Canadian Mental Health Association. (2013). Post-secondary stu- dent mental health: Guide to a systemic approach. Vancouver, BC: Washburn, C., Teo, S., Knodel, R., \& Morris, J.

Cash, M., \& Whittingham, K. (2010). What facets of mindfulness con- tribute to psychological 
This is a post-peer-review, pre-copyedit version of an article published in 'Current Psychology'. The final authenticated version is available online at: https://doi.org/10.1007/s12144-020-01056-w. The following terms of use apply: https://www.springer.com

well-being and depressive, anxious, and stress-related symptomatology? Mindfulness, 1(3), 177-182. https://doi.org/10.1007/s12671-010-0023-4.

Center for Behavioral Health Statistics and Quality. (2016). Key sub- stance use and mental health indicators in the United States: Results from the 2015 National Survey on Drug Use and Health (HHS Publication No. SMA 16-4984, NSDUH Series H-51). Retrieved from http://www.samhsa.gov/data/

Creswell, J. D. (2017). Mindfulness interventions. Annual Review of Psychology, 68, 491-516. https://doi.org/10.1146/annurev-psych- 042716-051139.

De Vries, S., Verheij, R. A., Groenewegen, P. P., \& Spreeuwenberg, P. (2003). Natural environments- healthy environments? An explorato- ry analysis of the relationship between greenspace and health. Environment and Planning, 35(10), 1717-1732. https://doi.org/10. 1068/a35111.

Diener, E. D., Emmons, R. A., Larsen, R. J., \& Griffin, S. (1985). The satisfaction with life scale. Journal of Personality Assessment, 49(1), 71-75. https://doi.org/10.1207/s15327752jpa4901_13.

Diener, E. (2000). Subjective well-being: The science of happiness and a proposal for a national index. American Psychologist, 55(1), 34-43. https://doi.org/10.1037/0003-066X.55.1.34.

Dunne, J. D. (2015). Buddhist styles of mindfulness: A heuristic ap- proach. In B. D. Ostafin, M. 
This is a post-peer-review, pre-copyedit version of an article published in 'Current Psychology'. The final authenticated version is available online at: https://doi.org/10.1007/s12144-020-01056-w. The following terms of use apply: https://www.springer.com

D. Robinson, \& B. P. Meier (Eds.), Handbook of mindfulness and self-regulation. New York: Springer. Fredrickson, B. L. (1998). What good are positive emotions? Review of General Psychology, 2(3), 300-319. https://doi.org/10.1037/1089- 2680.2.3.300.

Frumkin, H. (2013). The evidence of nature and the nature of evidence. American Journal of Preventive Medicine, 44(2), 196-197. https:// doi.org/10.1016/j.amepre.2012.10.016.

Galante, J., Dufour, G., Vainre, M., Wagner, A. P., Stochl, J., Benton, A., Lathia, N., Howarth, E., \& Jones, P. B. (2018). A mindfulness-based intervention to increase resilience to stress in university students (the mindful student study): A pragmatic randomised controlled trial. The Lancet Public Health, 3(2), e72-e81. https://doi.org/10.1016/ S24682667(17)30231-1.

Gallego, J., Aguilar-Parra, J. M., Cangas, A. J., Langer, Á. I., \& Mañas, I. (2014). Effect of a mindfulness program on stress, anxiety and de- pression in university students. The Spanish journal of psychology, 17. https://doi.org/10.1017/sjp.2014.102.

Gethin, R. (2011). On some definitions of mindfulness. Contemporary Buddhism, 12(1), 263227. https://doi.org/10.1080/14639947. 2011.564843.

Grossman, P., Niemann, L., Schmidt, S., \& Walach, H. (2004). Mindfulness-based stress reduction and health benefits: A meta- analysis. Journal of Psychosomatic Research, 57(1), 35-43. https://doi.org/10.1016/S0022-3999(03)00573-7.

Hanley, A. W., Derringer, S. A., \& Hanley, R. T. (2017). Dispositional mindfulness may be 
This is a post-peer-review, pre-copyedit version of an article published in 'Current Psychology'. The final authenticated version is available online at: https://doi.org/10.1007/s12144-020-01056-w. The following terms of use apply: https://www.springer.com

associated with deeper connections with nature. Ecopsychology, 9(4), 225-231. https://doi.org/10.1089/eco.2017.0018.

Hanley, A., Warner, A., \& Garland, E. L. (2015). Associations between mindfulness, psychological well-being, and subjective well-being with respect to contemplative practice. Journal of Happiness Studies, 16(6), 1423-1436. https://doi.org/10.1007/s10902-014- 9569-5.

Hart, R., Ivtzan, I., \& Hart, D. (2013). Mind the gap in mindfulness research: A comparative account of the leading schools of thought. Review of General Psychology, 17(4), 453466. https://doi.org/10. 1037/a0035212639947.2011.564843.

Hayes, A. F. (2017). Introduction to mediation, moderation, and condi- tional process analysis: A regression-based approach. New York: Guilford Publications.

Hayes, A. F. (2014). PROCESS for SPSS and SAS (version 2.11) [soft- ware]. Retrieved from http://www.afhayes.com/introduction-to- mediation-moderation-and-conditional-processanalysis.html.

Howell, A. J., Dopko, R. L., Passmore, H. A., \& Buro, K. (2011). Nature connectedness: Associations with well-being and mindfulness. Personality and Individual Differences, 51(2), 166-171. https:// doi.org/10.1016/j.paid.2011.03.037.

Ibrahim, A. K., Kelly, S. J., Adams, C. E., \& Glazebrook, C. (2013). A systematic review of studies of depression prevalence in university students. Journal of Psychiatric Research, 47(3), 391-400. https:// doi.org/10.1016/j.jpsychires.2012.11.015. 
This is a post-peer-review, pre-copyedit version of an article published in 'Current Psychology'. The final authenticated version is available online at: https://doi.org/10.1007/s12144-020-01056-w. The following terms of use apply: https://www.springer.com

Kabat-Zinn, J. (2003). Mindfulness-based interventions in context: Past, present, and future.

Clinical Psychology: Science and Practice, 10(2), 144-156.

https://doi.org/10.1093/clipsy/bpg016.

Kadziolka, M. J., Di Pierdomenico, E. A., \& Miller, C. J. (2016). Trait- like mindfulness

promotes healthy self-regulation of stress. Mindfulness, 7(1), 236-245.

https://doi.org/10.1007/s12671-015-0437-0.

Kaplan, R., \& Kaplan, S. (1989). The experience of nature: A psycho- logical perspective. CUP Archive.

Keng, S. L., Smoski, M. J., \& Robins, C. J. (2011). Effects of mindfulness on psychological health: A review of empirical studies. Clinical Psychology Review, 31(6), 1041-1056. https://doi.org/10.1016/j. cpr.2011.04.006.

Khoury, B., Knäuper, B., Pagnini, F., Trent, N., Chiesa, A., \& Carrière, K. (2017). Embodied mindfulness. Mindfulness., 8, 1160-1171. https://doi.org/10.1007/s12671-017-0700-7.

Khoury, B., Lecomte, T., Fortin, G., Masse, M., Therien, P., Bouchard, V., Chapleau, M. A., Paquin, K., \& Hofmann, S. G. (2013). Mindfulness-based therapy: A comprehensive meta-analysis. Clinical Psychology Review, 33(6), 763-771. https://doi.org/10. 1016/j.cpr.2013.05.005.

Khoury, B., Sharma, M., Ruth, S. E., \& Fournier, C. (2015). Mindfulness-based stress reduction 
This is a post-peer-review, pre-copyedit version of an article published in 'Current Psychology'. The final authenticated version is available online at: https://doi.org/10.1007/s12144-020-01056-w. The following terms of use apply: https://www.springer.com

for healthy individuals: A Meta-analysis. Journal of Psychosomatic Research, 78, 519528. https://doi.org/10.1016/j.jpsychores.2015.03.009.

Lanz, M., \& Tagliabue, S. (2007). Do I really need someone to become adult? Romantic relationships in emerging adulthood. Journal of Adolescent Research, 22, 531-549. https://doi.org/10.1177/0743558407306713.

Lin, Y. H., Tsai, C. C., Sullivan, W. C., Chang, P. J., \& Chang, C. Y. (2014). Does awareness effect the restorative function and percep- tion of street trees? Frontiers in Psychology, 5, 906. https://doi.org/ 10.3389/fpsyg.2014.00906.

Macek, P., Bejček, J., \& Vaníčková, J. (2007). Contemporary Czech emerging adults:

Generation growing up in the period of social changes. Journal of Adolescent Research, 22, 444-475. https://doi. org/10.1177/0743558407305417.

Mantler, A., \& Logan, A. C. (2015). Natural environments and mental health. Advances in Integrative Medicine, 2(1), 5-12. https://doi.org/ 10.1016/j.aimed.2015.03.002.

Mayer, F. S., Frantz, C. M., Bruehlman-Senecal, E., \& Dolliver, K. (2009). Why is nature beneficial? The role of connectedness to na- ture. Environment and Behavior, 41(5), 607643. https://doi.org/10. 1177/0013916508319745.

Mayseless, O., \& Scharf, M. (2003). What does it mean to be an adult? The Israeli experience. New Directions in Child and Adolescent Development, 100, 5-20. https://doi.org/10.1002/cd.71. 
This is a post-peer-review, pre-copyedit version of an article published in 'Current Psychology'. The final authenticated version is available online at: https://doi.org/10.1007/s12144-020-01056-w. The following terms of use apply: https://www.springer.com

McMahan, E. A., \& Estes, D. (2015). The effect of contact with natural environments on positive and negative affect: A meta-analysis. The Journal of Positive Psychology, 10(6), 507519. https://doi.org/10. 1080/17439760.2014.994224.

Nisbet, E. K., Zelenski, J. M., \& Murphy, S. A. (2009). The nature relatedness scale: Linking individuals' connection with nature to environmental concern and behavior. Environment and Behavior, 41(5), 715-740. https://doi.org/10.1177/0956797611418527.

Nisbet, E. K., Zelenski, J. M., \& Murphy, S. A. (2011). Happiness is in our nature: Exploring nature relatedness as a contributor to subjec- tive well-being. Journal of Happiness Studies, 12(2), 303-322. https://doi.org/10.1007/s10902-010-9197-7.

Orians, G. H. (1980). Habitat selection: General theory and applications to human behavior. The Evolution of Human Social Behavior.

Passmore, H. A., \& Howell, A. J. (2014). Nature involvement increases hedonic and eudaimonic well-being: A two-week experimental study. Ecopsychology, 6(3), 148-154. https://doi.org/10.1089/eco. 2014.0023.

Pavot, W., \& Diener, E. (1993). The affective and cognitive context of self-reported measures of subjective well-being. Social Indicators Research, 28(1), 1-20. https://doi.org/10.1007/bf01086714.

Pearson, Janz and Ali (2013). Health at a glance: Mental and substance use disorders in Canada. Statistics Canada Catalogue, 82, 624-X. 
This is a post-peer-review, pre-copyedit version of an article published in 'Current Psychology'. The final authenticated version is available online at: https://doi.org/10.1007/s12144-020-01056-w. The following terms of use apply: https://www.springer.com

Regehr, C., Glancy, D., \& Pitts, A. (2013). Interventions to reduce stress in university students:

A review and meta- analysis. Journal of Affective Disorders, 148(1), 1-11. https://doi.org/10.1016/j.jad.2012.11.026.

Richardson, M., \& Hallam, J. (2013). Exploring the psychological re- wards of a familiar semirural landscape: Connecting to local nature through a mindful approach. The Humanistic Psychologist, 41(1), 35-53. https://doi.org/10.1080/08873267.2012.732156.

Ryan, R. M., Weinstein, N., Bernstein, J., Brown, K. W., Mistretta, L., \& Gagne, M. (2010). Vitalizing effects of being outdoors and in nature. Journal of Environmental Psychology, 30, 159-168. https://doi.org/ 10.1016/j.jenvp.2009.10.009.

Schutte, N. S., \& Malouff, J. M. (2011). Emotional intelligence mediates the relationship between mindfulness and subjective well-being. Personality and Individual Differences, 50(7), 1116-1119. https:// doi.org/10.1016/j.paid.2011.01.037.

Schutte, N. S., \& Malouff, J. M. (2018). Mindfulness and connectedness to nature: A metaanalytic investigation. Personality and Individual Differences, 127, 10-14. https://doi.org/10.1016/j.paid.2018.01. 034.

Shanahan, D., Lin, B., Bush, R., Gaston, K., Dean, J., Barber, E., \& Fuller, R. (2015). Toward improved public health outcomes from urban nature. American Journal of Public Health, 105(3), 470-477. https://doi.org/10.2105/ajph.2014.302324.

Shapiro, S. L., Brown, K. W., Thoresen, C., \& Plante, T. G. (2011). The moderation of 
This is a post-peer-review, pre-copyedit version of an article published in 'Current Psychology'. The final authenticated version is available online at: https://doi.org/10.1007/s12144-020-01056-w. The following terms of use apply: https://www.springer.com

mindfulness-based stress reduction effects by trait mindfulness: Results from a randomized controlled trial. Journal of Clinical Psychology, 67(3), 267-277. https://doi.org/10.1002/ jclp.20761.

Soysa, C. K., \& Wilcomb, C. J. (2015). Mindfulness, self-compassion, self-efficacy, and gender as predictors of depression, anxiety, stress, and well-being. Mindfulness, 6(2), 217-226. https://doi.org/10. 1007/s12671-013-0247-1.

Statistics Canada. (2015). Canadian Tobacco, Alcohol and Drugs Survey (CTADS): 2015 summary. Retrieved from https://www.canada.ca/ en/health-canada/services/canadiantobacco-alcohol-drugs-survey/ 2015-summary.html

Tabachnick, B. G., Fidell, L. S., \& Ullman, J. B. (2007). Using multivar- iate statistics (Vol. 5). Boston: Pearson.

Unsworth, S., Palicki, S. K., \& Lustig, J. (2016). The impact of mindful meditation in nature on self-nature interconnectedness. Mindfulness, 7(5), 1052-1060. https://doi.org/10.1007/s12671-016-0542-8.

Walsh, R. (2011). Lifestyle and mental health. American Psychologist, 66, 579-592.

Watson, D., Clark, L. A., \& Tellegen, A. (1988). Development and val- idation of brief measures of positive and negative affect: The PANAS scales. Journal of Personality and Social Psychology, 54(6), 1063-1070. https://doi.org/10.1037//0022-3514.54.6.1063.

Wilson, E. O. (1984). Biophilia. Cambridge: Harvard University Press. Zelenski, J. M., \& 
This is a post-peer-review, pre-copyedit version of an article published in 'Current Psychology'. The final authenticated version is available online at: https://doi.org/10.1007/s12144-020-01056-w. The following terms of use apply: https://www.springer.com

Nisbet, E. K. (2014). Happiness and feeling connected: The distinct role of nature relatedness. Environment and Behavior, 46(1), 3-23.

https://doi.org/10.1177/0013916512451901.

\section{Tables and Figures}

\begin{tabular}{|c|c|c|}
\hline & Univer & \\
\hline & $\mathbf{M}$ & SD \\
\hline Nature relatedness & 3.58 & .54 \\
\hline Positive affect & 31.06 & 8.27 \\
\hline Negative affect & 26.31 & 7.44 \\
\hline Life satisfaction & 22.46 & 6.77 \\
\hline Non-reacting & 19.65 & 4.13 \\
\hline Non-judging & 23.49 & 7.16 \\
\hline Acting with awareness & 23.23 & 6.24 \\
\hline Describing & 25.85 & 6.63 \\
\hline Observing & 26.62 & 5.40 \\
\hline
\end{tabular}


This is a post-peer-review, pre-copyedit version of an article published in 'Current Psychology'. The final authenticated version is available online at: https://doi.org/10.1007/s12144-020-01056-w. The following terms of use apply: https://www.springer.com

\begin{tabular}{|c|c|c|c|c|c|c|c|c|c|}
\hline & 1 & 2 & 3 & 4 & 5 & 6 & 7 & 8 & 9 \\
\hline 1. Nature relatedness & 1 & & & & & & & & \\
\hline 2. Positive affect & $.24^{* *}$ & 1 & & & & & & & \\
\hline 3. Negative affect & -.02 & $-.28 * *$ & 1 & & & & & & \\
\hline 4. Life satisfaction & $.16^{*}$ & $.57 * *$ & $-.39 * *$ & 1 & & & & & \\
\hline 5. Non-reacting & $.15^{*}$ & $.31 * *$ & $-.29 * *$ & $.33 * *$ & 1 & & & & \\
\hline 6. Non-judging & .04 & $.18 * *$ & $-.39 * *$ & $.32 * *$ & $.24 * *$ & 1 & & & \\
\hline $\begin{array}{l}\text { 7. Acting with } \\
\text { awareness }\end{array}$ & .08 & $.44 * *$ & $-.46^{* *}$ & $.40^{* *}$ & $.32^{* *}$ & $.39 * *$ & 1 & & \\
\hline 8. Describing & $.13^{*}$ & $.38 * *$ & $-.25^{* *}$ & $.38 * *$ & $.23^{* *}$ & $.22 * *$ & $.38 * *$ & 1 & \\
\hline 9. Observing & $.36^{* *}$ & $.31 * *$ & -.01 & $.22 * *$ & $.20^{* *}$ & -.09 & .05 & $.15^{*}$ & 1 \\
\hline
\end{tabular}

\begin{tabular}{|c|c|c|c|c|c|c|c|c|c|}
\hline \multicolumn{10}{|c|}{$\begin{array}{l}\text { Table } 3 \text { Mediation Models: The Effect of Mindfulness Facets on the Relationship Between } \\
\text { Nature Relatedness and Subjective Well-Being }\end{array}$} \\
\hline Model & $\mathbf{X}$ & $\mathbf{Y}$ & M & $\begin{array}{l}X \text { to } M \\
\text { (B) }\end{array}$ & $\begin{array}{l}\text { M to } Y \\
\text { ( } \beta)\end{array}$ & $c$ & $c^{\prime}$ & $a b$ & $95 \% \mathrm{CI}$ \\
\hline 1 & NRS & PA & NR & $1.14 *$ & $.56^{* * * *}$ & $3.70^{* * * *}$ & $3.06^{* * *}$ & .63 & {$[.10,1.27]$} \\
\hline 2 & NRS & PA & NJ & .57 & $.19^{* *}$ & $3.70 * * *$ & $3.59 * * *$ & .11 & {$[-.21, .57]$} \\
\hline 3 & NRS & PA & A & .90 & $.56^{* * * *}$ & $3.70^{* * * *}$ & $3.19 * * *$ & .50 & {$[-.27,1.38]$} \\
\hline 4 & NRS & $\mathrm{PA}$ & $\mathrm{D}$ & $1.52^{*}$ & $.44 * * *$ & $3.70 * * *$ & $3.03 * * *$ & .67 & {$[-.02,1.47]$} \\
\hline 5 & NRS & $\mathrm{PA}$ & $\mathrm{O}$ & $3.55^{* * *}$ & $.40 * * *$ & $3.70 * * *$ & $2.29 *$ & 1.41 & {$[.62,2.39]$} \\
\hline 6 & NRS & NA & NR & $1.14^{*}$ & $-.53 * * *$ & -.31 & .29 & -.60 & $\begin{array}{l}-1.22, \\
-.09]\end{array}$ \\
\hline 7 & NRS & NA & NJ & .57 & $-.41 * * *$ & -.31 & -.08 & -.23 & {$[-.98, .47]$} \\
\hline 8 & NRS & NA & A & .90 & $-.46^{* * * *}$ & -.31 & .18 & -.49 & {$[-1.37, .29]$} \\
\hline 9 & NRS & NA & $\mathrm{D}$ & $1.52 *$ & $-.28 * * *$ & -.31 & .11 & -.43 & {$[-.98, .01]$} \\
\hline 10 & NRS & NA & $\mathrm{O}$ & $3.55^{* * *}$ & .01 & -.31 & -.33 & .02 & {$[-.64, .72]$} \\
\hline
\end{tabular}


This is a post-peer-review, pre-copyedit version of an article published in 'Current Psychology'. The final authenticated version is available online at: https://doi.org/10.1007/s12144-020-01056-w. The following terms of use apply: https://www.springer.com

\begin{tabular}{|c|c|c|c|c|c|c|c|c|c|}
\hline 11 & NRS & $\mathrm{LS}$ & NR & $1.14 *$ & $.51 * * *$ & $1.20 *$ & 1.41 & .58 & {$[.11,1.17]$} \\
\hline 12 & NRS & LS & NJ & .57 & $.30 * * *$ & $1.20 *$ & $1.83 *$ & .17 & {$[-.36, .78]$} \\
\hline 13 & NRS & LS & $\mathrm{A}$ & .90 & $.42 * * *$ & $1.20 *$ & $1.62 *$ & .38 & {$[-.25,1.06]$} \\
\hline 14 & NRS & $\mathrm{LS}$ & $\mathrm{D}$ & $1.52 *$ & $.37 * * *$ & $1.20 *$ & 1.43 & .56 & {$[-.01,1.25]$} \\
\hline 15 & NRS & $\mathrm{LS}$ & $\mathrm{O}$ & $3.55 * * *$ & $.23 * *$ & $1.20 *$ & 1.17 & .82 & {$[.15,1.62]$} \\
\hline \multicolumn{10}{|c|}{$\begin{array}{l}{ }^{*} \mathrm{p}<.05 ; * * \mathrm{p}<.01 ; * * * \mathrm{p}<.001 ; \beta=\text { pathway beta values; } \mathrm{c}=\text { total effect; } \mathrm{c} \text { ' = direct effect; } \\
\mathrm{ab}=\text { indirect effect; } 95 \% \mathrm{CI}=95 \% \text { confidence interval of the indirect effect; NRS = Nature } \\
\text { Relatedness Scale; PA = Positive Affect; NA = Negative Affect; LS = Life Satisfaction; } \\
\text { NR = Non-Reactivity; NJ = Non-Judging; A = Acting with Awareness; D = Describing; } \\
\mathrm{O}=\text { Observing }\end{array}$} \\
\hline
\end{tabular}

Figures Depicting Mediation Models

Fig. 1 Model depicting the

mediational role of non-reactivity

on the association between nature

relatedness and positive affect. * $p$

$<.05, * * * *<<.001$

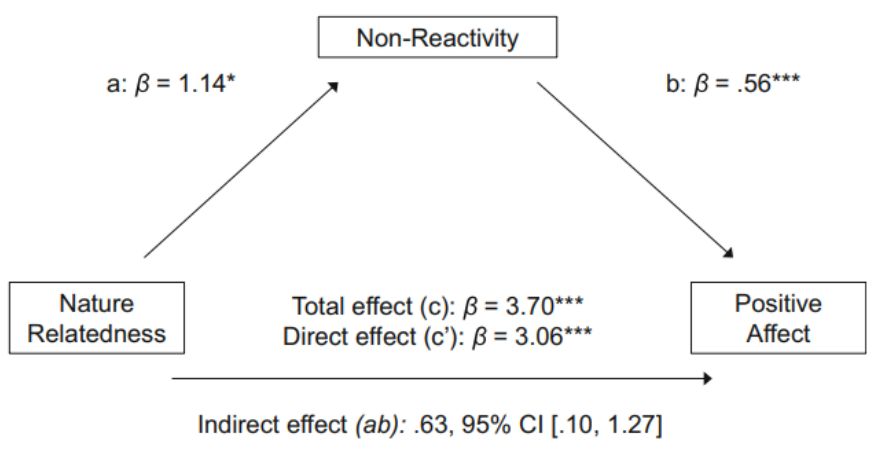

Fig. 2 Model depicting the

mediational role of non-reactivity

on the association between nature

relatedness and life satisfaction.

$* p<.05, * * * p<.001$

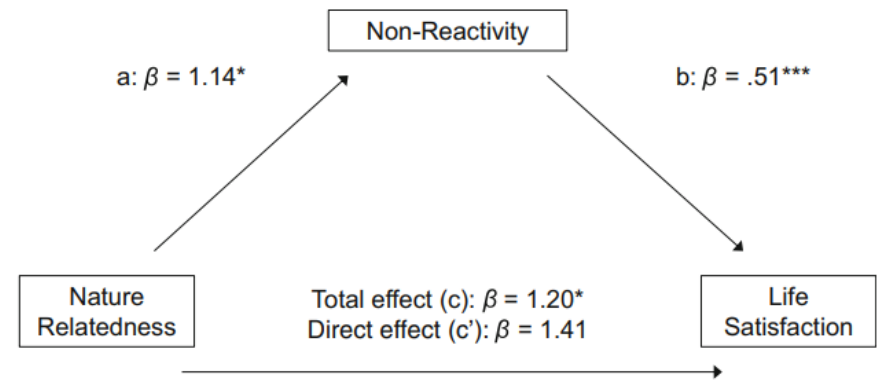

Indirect effect $(a b): .58,95 \% \mathrm{Cl}[.11,1.17]$ 
This is a post-peer-review, pre-copyedit version of an article published in 'Current Psychology'. The final authenticated version is available online at: https://doi.org/10.1007/s12144-020-01056-w. The following terms of use apply: https://www.springer.com

Fig. 3 Model depicting the mediational role of non-reactivity on the association between nature relatedness and negative affect. $* p<.05, * * * p<.001$
Fig. 4 Model depicting the mediational role of observing on the association between nature relatedness and positive affect. ${ }^{*} p<.05, * * * k<.001$
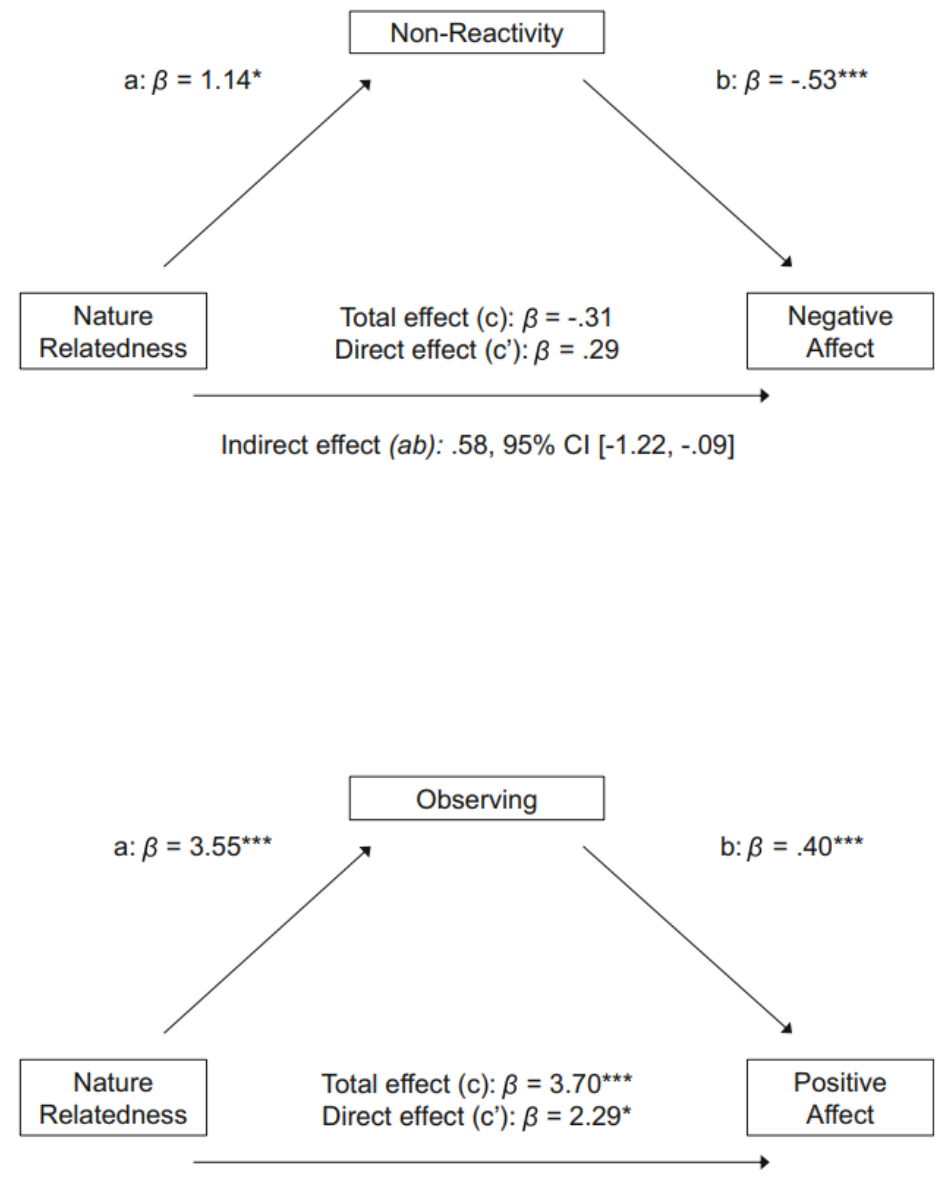

Indirect effect (ab): $1.41,95 \% \mathrm{Cl}[.62,2.40]$

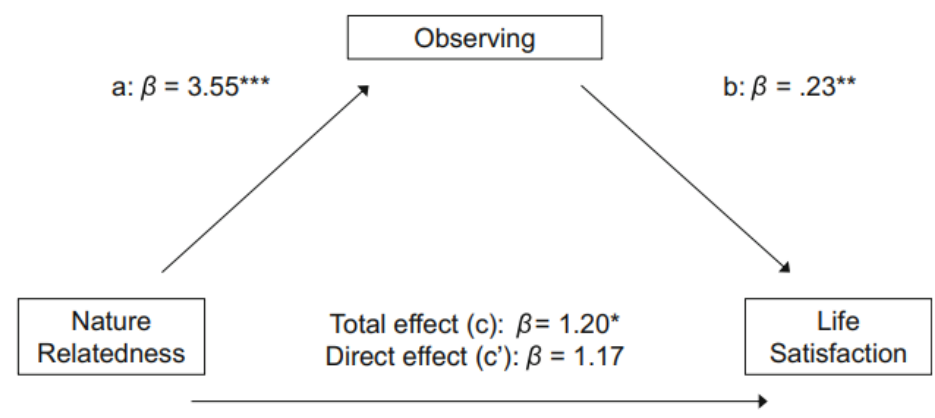

Indirect effect (ab): .82, 95\% Cl [.02, .24]
Fig. 5 Model depicting the mediational role of observing on the association between nature relatedness and life satisfaction. ${ }^{*} p<.05,{ }^{* *} p<.01 * * * * x<.001$ 
This is a post-peer-review, pre-copyedit version of an article published in 'Current Psychology'. The final authenticated version is available online at: https://doi.org/10.1007/s12144-020-01056-w. The following terms of use apply: https://www.springer.com

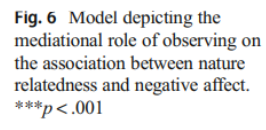

*** $p<.001$

Fig. 7 Model depicting the

mediational role of non-judging

on the association between nature

relatedness and positive affect.

$* * p<.01, * * * p<.001$
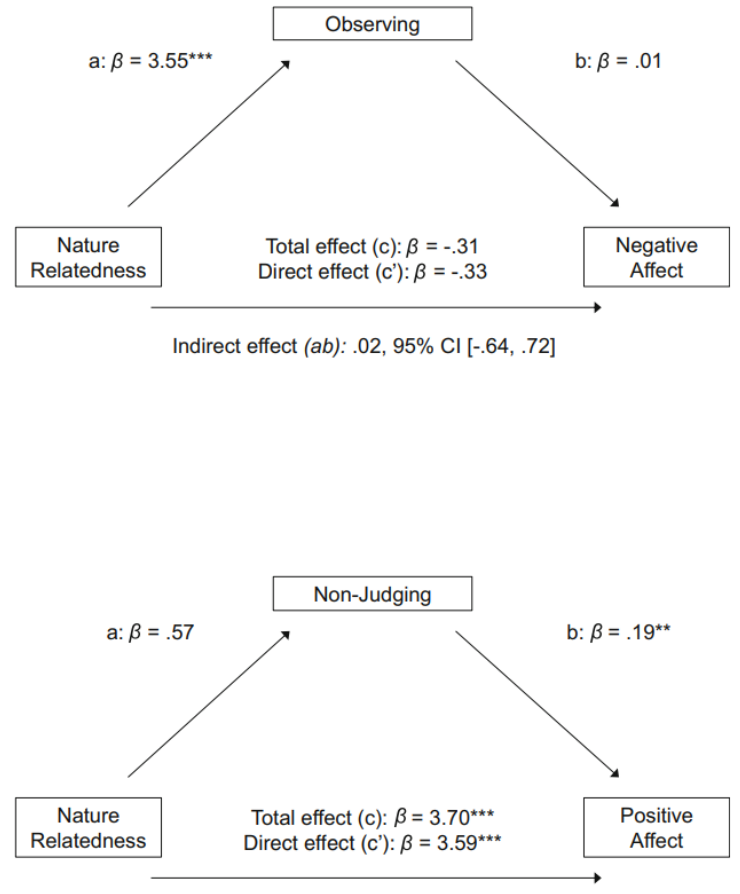

Indirect effect (ab): .11, 95\% Cl [-.21, .57]

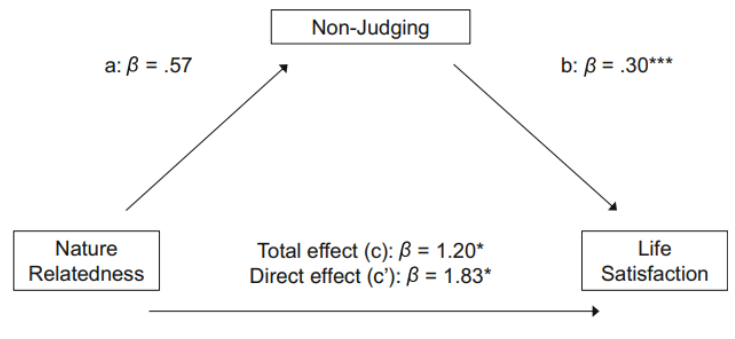

Indirect effect (ab): .17, 95\% Cl [-.36, .78]
Fig. 8 Model depicting the mediational role of non-judging on the association between nature relatedness and life satisfaction. ${ }^{*} p<.05,{ }^{* * *} p<.001$ 
This is a post-peer-review, pre-copyedit version of an article published in 'Current Psychology'. The final authenticated version is available online at: https://doi.org/10.1007/s12144-020-01056-w. The following terms of use apply: https://www.springer.com

Fig. 9 Model depicting the mediational role of non-judging on the association between nature relatedness and negative affect. $* * * p<.001$
Fig. 10 Model depicting the mediational role of describing on the association between nature relatedness and positive affect. * $p$ $<.05, * * * *<<.001$

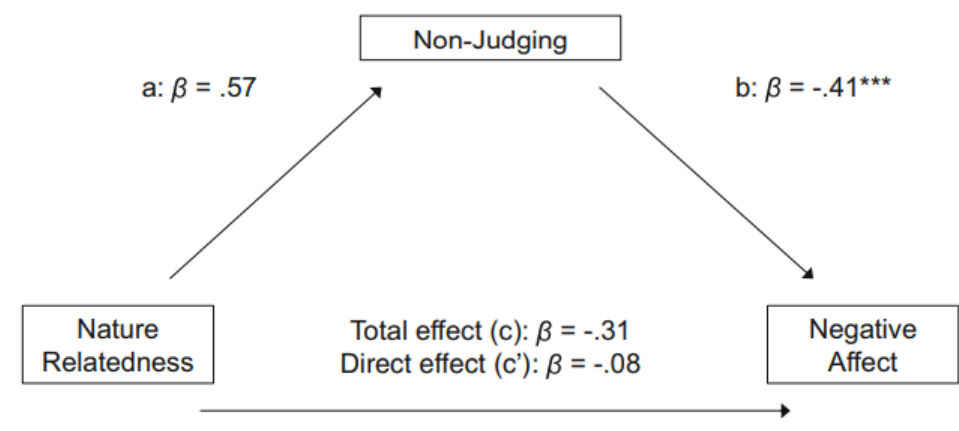

Indirect effect $(a b):-.23,95 \% \mathrm{Cl}[-.98, .47]$

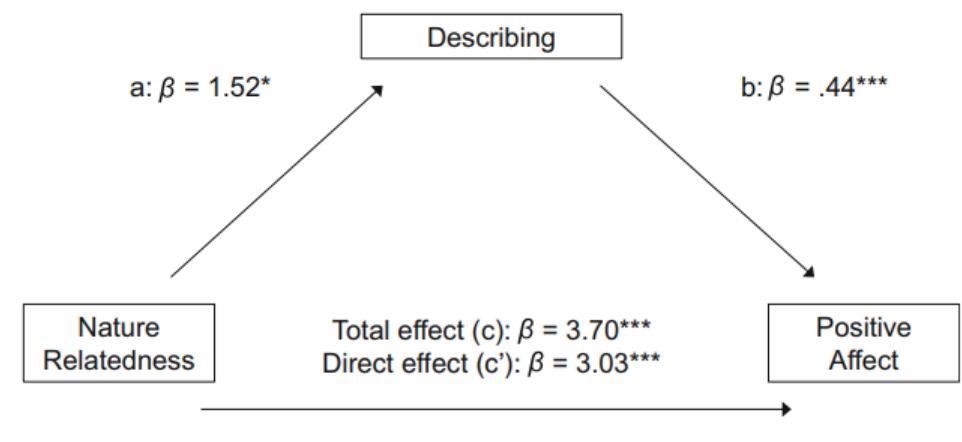

Indirect effect $(a b): .67,95 \% \mathrm{Cl}[-.02,1.47]$

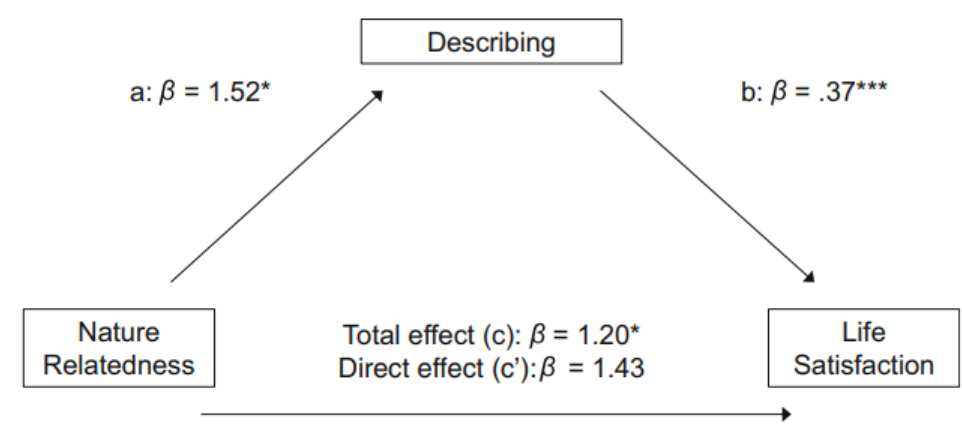

Indirect effect (ab): .56, 95\% Cl [-.01, 1.25]
Fig. 11 Model depicting the mediational role of describing on the association between nature relatedness and life satisfaction. $* p<.05,{ }^{*} * * *<<.001$ 
This is a post-peer-review, pre-copyedit version of an article published in 'Current Psychology'. The final authenticated version is available online at: https://doi.org/10.1007/s12144-020-01056-w. The following terms of use apply: https://www.springer.com

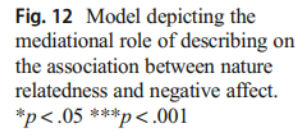

Fig. 13 Model depicting the mediational role of acting with awareness on the association between nature relatedness and positive affect. $* * * p<.001$

Fig. 14 Model depicting the mediational role of acting with awareness on the association between nature relatedness and life satisfaction. ${ }^{*} p<.05$,

**** $p<.001$
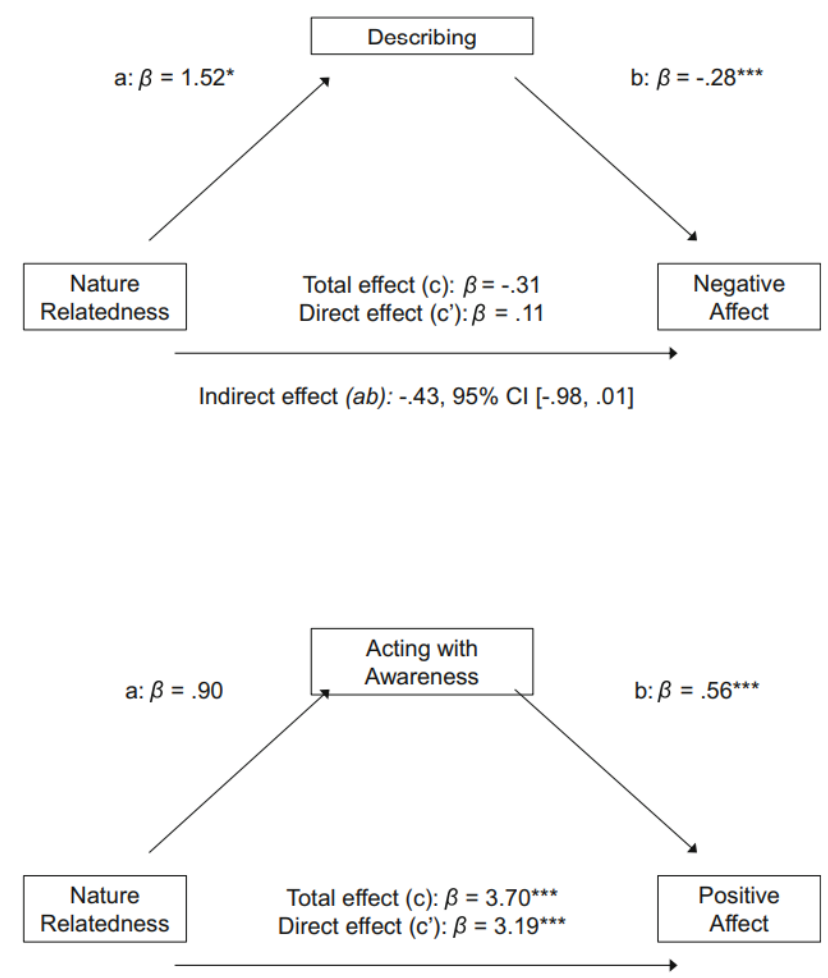

Indirect effect $(a b): .50,95 \% \mathrm{Cl}[-.27,1.38]$

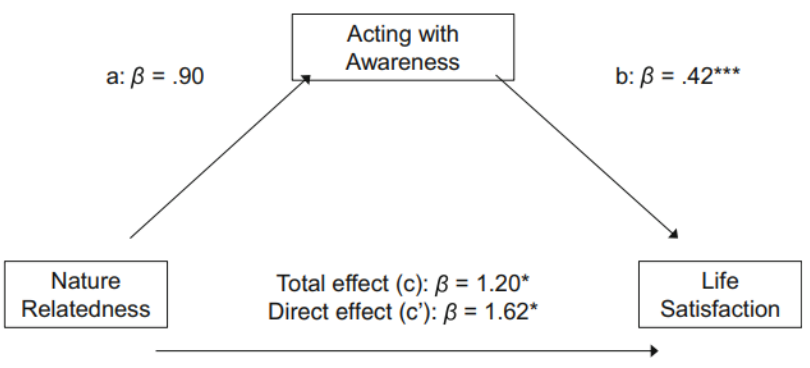

Indirect effect (ab): .38, 95\% Cl [-.25, 1.06] 
This is a post-peer-review, pre-copyedit version of an article published in 'Current Psychology'. The final authenticated version is available online at: https://doi.org/10.1007/s12144-020-01056-w. The following terms of use apply: https://www.springer.com
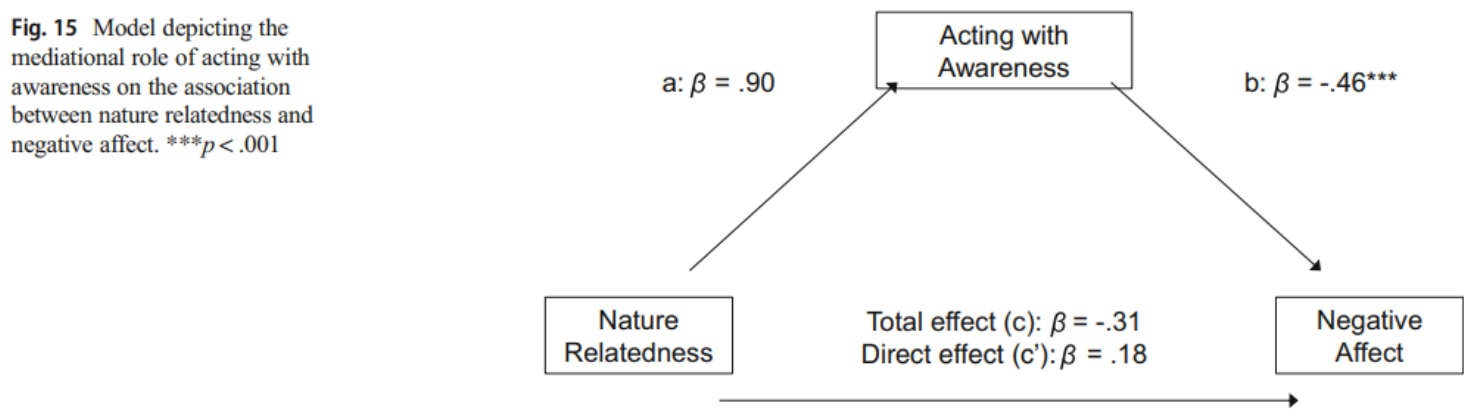

Indirect effect $(a b):-.49,95 \% \mathrm{Cl}[-1.37, .29]$ 